\title{
An infrequent complication of lead extraction - distal part of a lead rupture and surprising self-solution of the problem
}

\author{
Andrzej Kutarski1,A-F, Radoslaw Pietura ${ }^{2, A-E}$, Maciej Polewczyk ${ }^{3, A-E}$, Anna Polewczyk ${ }^{4, A-E}$ \\ A - Research concept and design, B - Collection and/or assembly of data, C - Data analysis and interpretation, \\ D - Writing the article, E - Critical revision of the article, F - Final approval of article \\ 1 Department of Cardiology, Medical University of Lublin, Poland \\ 2 Department of Radiography Medical University of Lublin, Poland \\ 3 Acute Cardiac Care Unit, Swietokrzyskie Cardiology Center, Kielce, Poland \\ 4 The Jan Kochanowski University, Department of Medicine and Health Sciences, Kielce, Poland
}

Address for correspondence:

Andrzej Kutarski, Department of Cardiology, Medical University of Lublin, Poland

email: a_kutarski@yahoo.com

Radoslaw Pietura, Department of Radiography Medical University of Lublin, Poland

email: radoslawpietura@hotmail.com

Maciej Polewczyk, Acute Cardiac Care Unit, Swietokrzyskie Cardiology Center, Kielce, Poland

email: maciek.polewczyk@gmail.com

Anna Polewczyk, The Jan Kochanowski University, Department of Medicine and Health Sciences, Kielce, Poland email: annapolewczyk@wp.pl

\section{Introduction}

Lead breakage is a known complication of transvenous lead extraction (TLE) which may occur regardless of extraction techniques and tools, such as mechanical systems (telescopic Byrd dilators, Femoral Working Station), or energy equipped catheters (laser, radiofrequency energy). Accidental breakage of ingrown, chronically implanted leads is more frequent in the regions of strong fibrotic scar tissue covering the lead along its course - especially if calcified adherences on leads appear. The frequency of this complication is estimated at several percent ${ }^{[1-7]}$. The role of locking stylets is partially limited, because they often cannot be introduced into the distal part of the lead due to significant lead curvature or presence of fluid tissue inside the wire ${ }^{[8,9]}$. Usually the tip of a broken lead is remaining, fixed to the myocardium by fibrotic tissue with variable length of the lead fragment. Occasionally, the broken distal part of a lead is dislocated and wanders in the heart cavities ${ }^{[10-12]}$. Among 2269 TLE procedures and 3809 chronically implanted lead extraction procedures, we encountered two very similar and surprising solutions for extraction of broken lead parts. For comparison, we additionally present one "typical" case.

\section{Key words:}

complications of lead extraction, lead breakage, lead fragment accidental extraction, transvenous lead extraction.

\section{Case 1}

A 68-year-old Caucasian man with ischemic heart disease and a 7-year-old dual chamber (DDD) pacing system implanted due to second degree atrioventricular (AV) block was referred to our department because of atrial lead dysfunction (crush syndrome). He had another abandoned 10-year-old ventricular lead and significantly narrowed subclavian and anonymous veins (figure $1 \mathrm{~A}$ ). We decided to extract the non-functional atrial and abandoned ventricular lead for recapture of venous entry. Both leads were extracted with a mechanical system (polypropylene telescopic Byrd Dilators, Cook) using a subclavian approach. The atrial lead was extracted without problems, unbroken (figure $1 \mathrm{~B}$ ). The ventricular lead was separated from the right ventricle (with its tip), but during dissection of connecting tissue bridges with the right atrium (RA) wall (figure $1 \mathrm{C}$ ), the distal end of the lead with anodal ring and $2 \mathrm{~cm}$ conductor fragment was cut, but remained in the right atrium. The main part of the lead was removed via the Byrd dilator and a new atrial lead was implanted (figure 1C,D). 


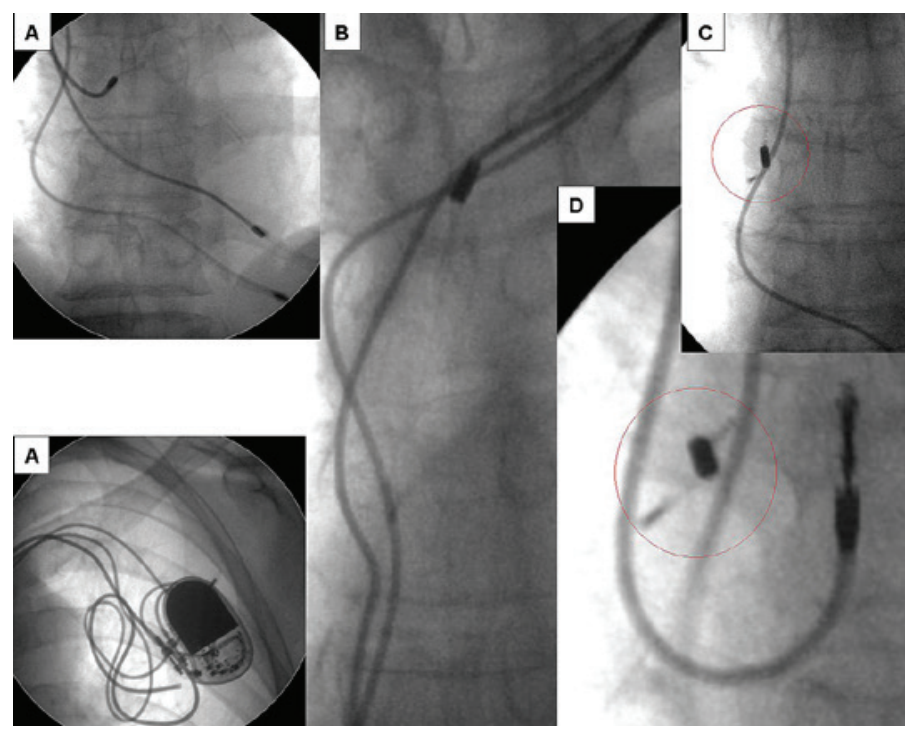

Figure 1 A-D.

On the next day we found the lost lead fragment low in the right atrium (figure $2 \mathrm{~A}$ ); to prevent its dislodgment into the right ventricle or other part of the cardiovascular system, we decided to remove it using the femoral approach and Dotter retrieval basket catheter (Cook Inc, USA). The procedure was easy and successful (figure $2 \mathrm{~B}, \mathrm{C}, \mathrm{D}$ ). This case is representative for accidental lead breakage and the conventional solution of the problem.

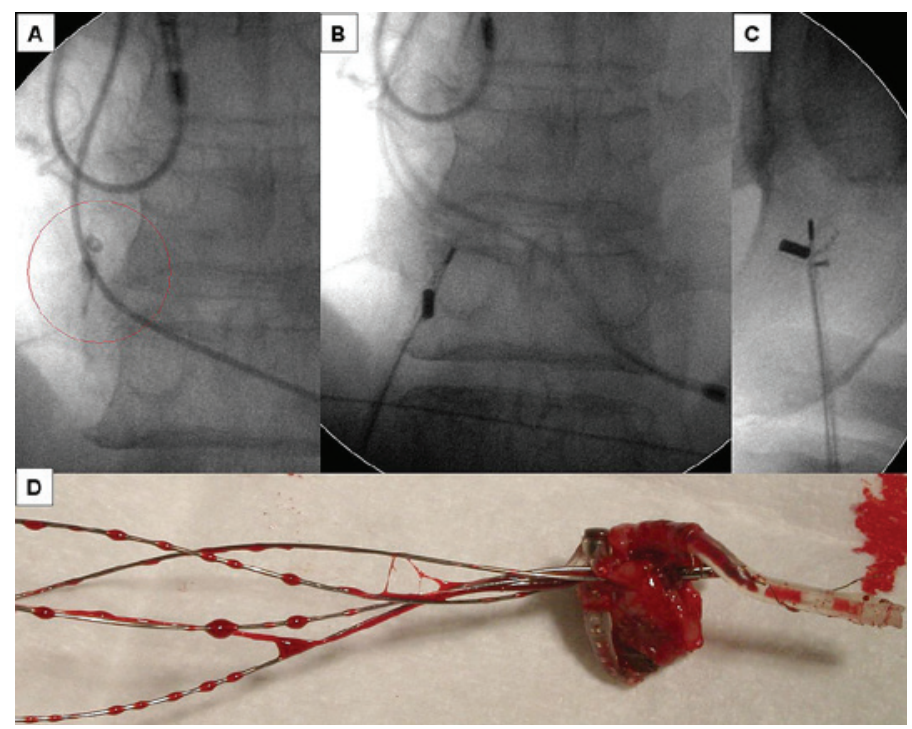

Figure 2 A-D.

Case 2

A 61-year-old Caucasian man with ischemic cardiomyopathy and four pacemaker leads ( 2 atrial and 2 ventricular leads of dwelling time 8-11 years), with permanent atrial fibrillation, was referred to our department for lead extraction, venous access recapture and single chamber cardioverter-defibrillator (ICD-VVI) implantation. All leads were extracted with a mechanical system (polypropylene telescopic Byrd Dilators, Cook, USA) using the subclavian approach. During the very difficult bipolar atrial lead extraction (due to tough scar tissue in subclavian and anonymous veins) the lead was stretched and finally broken (figure $3 \mathrm{~A}, \mathrm{~B}$ ). In the RA there remained its tip with the $2 \mathrm{~cm}$ metal conductor. We left the problem for the next steps of the procedure and we started bipolar ventricular lead extraction. When the Byrd dilator was at the level of the mid-atrium, the distal part of the atrial lead separated from the wall (figure $3 \mathrm{C}$ ). We were greatly surprised that both distal parts of the leads were inside the Byrd dilator and were easily removed (figure $3 \mathrm{D}, \mathrm{E}$ ). The final part of the procedure was standard: both remaining unipolar leads were extracted and, using the Byrd dilator, the guide-wire was inserted into the superior vena cava (SVC) and by the standard introducer the ICD lead was implanted. During the patient's hospital stay and during the 2-year follow-up no complications were observed.

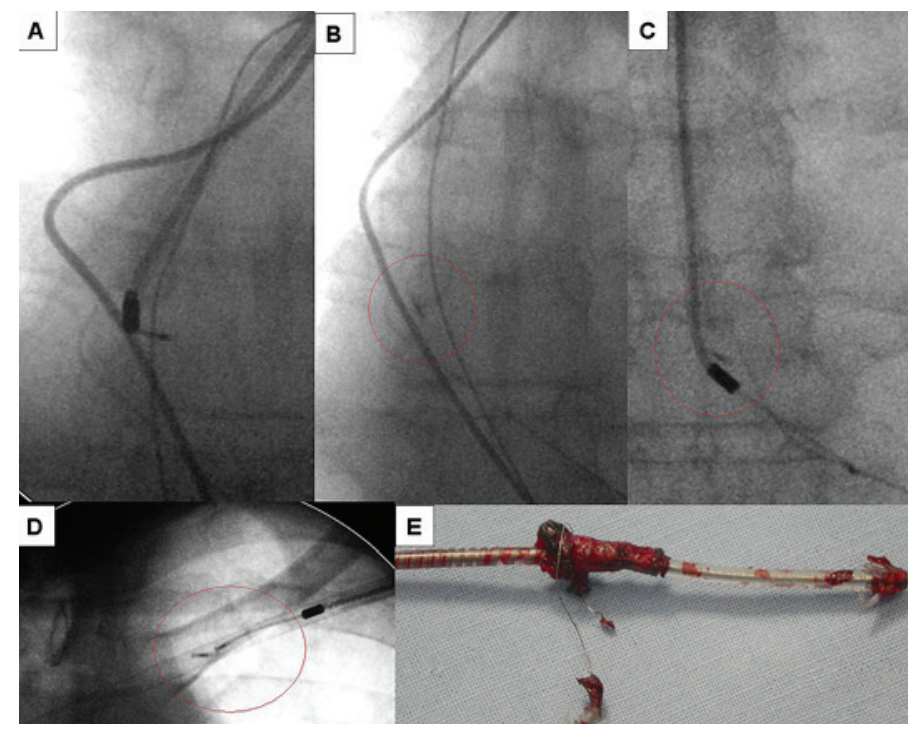

Figure 3 A-E.

\section{Case 3}

A 79-year-old Caucasian man with ischemic heart disease and a DDD system implanted (11 years before the current hospitalization) due to second degree AV block was referred to our department with severe local pocket infection which started after the last unit replacement 2 years earlier. The patient was qualified for TLE. All leads were extracted with the mechanical system using the subclavian approach. Due to excessive scar tissue in the subclavian and anonymous veins the metal sheath was used transiently. The atrial lead was stretched and finally broken (figure $4 \mathrm{~A}, \mathrm{~B}, \mathrm{C}, \mathrm{D}$ ). In the right atrium there remained its tip with a difficult-to-evaluate length of internal spiral metal conductor with its silicone tube. As in the previous case, we temporarily left the problem and began ventricular lead extraction (figure $4 \mathrm{E}$ ). When the Byrd dilator was in the SVC, the distal part of atrial lead was liberated using minimal tension necessary for working with dilators (figure $4 \mathrm{~F}$ ). Once again we were most surprised to find both leads (the extracted lead and the lost lead internal fragment) together in the Byrd dilator (figure $4 \mathrm{G}, \mathrm{H}$ ). Complicated lead fragment extraction using the femoral approach, lasso or basket catheter was avoided. After appropriate antibiotic therapy, the patient received another right-sided DDD after several months. 


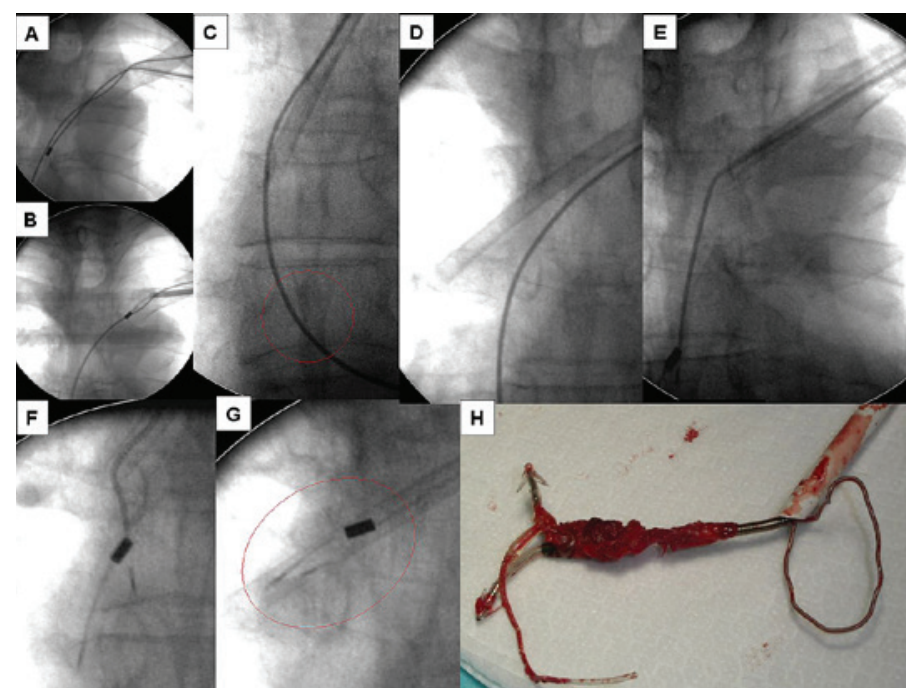

Figure 4 A-4.

\section{Discussion}

In the literature we can find many reports of the problem of lead breakage during extraction ${ }^{[1-11]}$. If the fragment is shorter than $4 \mathrm{~cm}$, the procedure is finished and its result is classified as a "partial success" ${ }^{[12]}$. If the lead remnant is longer, it is usually extracted with transvenous techniques (usually the femoral approach) using the Femoral Working Station, Dotter basket catheter (Cook, USA), lasso catheters or an Amplatz goose neck snare kit (Covidien, Ireland) for intravascular foreign body retrieval ${ }^{[1-11]}$. Rarely other more sophisticated tools such as steerable transseptal sheaths are used ${ }^{[13]}$. However, a multidisciplinary approach is recommended to ensure proper management in particularly complicated cases ${ }^{[14,15]}$

There are no exact recommendations regarding the direction of Byrd dilator rotation, especially in the intracardiac region. We may only speculate that in both presented cases predominance of single-side rotation caused rolling of the broken lead fragment over the lead extracted at that moment, which secondarily caused their strong fixation and finally enabled successful extraction without another complicated procedure.

\section{Conclusions:}

1. During the procedure of lead extraction the distal fragment may be separated from the lead body.

2. Predominant single-side Byrd dilator rotation during extraction of the other lead may roll the broken lead fragment over the currently extracted lead and enable its accidental removal.

\section{References}

1. Byrd CL, Wilkoff BL, Love CJ, Sellers TD, Reiser C. Clinical study of the laser sheath for lead extraction: the total experience in the United States. Pacing Clin Electrophysiol. 2002;25:804-8.

2. Byrd CL, Wilkoff BL, Love CJ et al. Intravascular extraction of problematic or infected permanent pace- maker leads: 1994-1996. U.S. Extraction Database, MED Institute. Pacing Clin Electrophysiol. 1999;22:1348-57.

3. Rusanov A, Spotnitz HM. A 15-year experience with permanent pacemaker and defibrillator lead and patch extractions. Ann Thorac Surg. 2010;89:44-50

4. Kennergren C, Bjurman C, Wiklund R, Gäbel J. A single-centre experience of over one thousand lead extractions. Europace. 2009;11:612-7.

5. Calvagna GM, Evola R, Scardace G, Valsecchi S. Single-operator experience with a mechanical approach for removal of pacing and implantable defibrillator leads. Europace. 2009;11:1505-9

6. Bongiorni MG, Soldati E, Zucchelli G et al. Transvenous removal of pacing and implantable cardiac defibrillating leads using single sheath mechanical dilatation and multiple venous approaches: high success rate and safety in more than 2000 leads. Eur Heart J. 2008;29:2886-93.

7. Kantharia BK, Kutalek SP. Extraction of pacemaker and implantable cardioverter defibrillator leads. Curr Opin Cardiol. 1999;14:44-51.

8. Byrd CL, Schwartz SJ, Hedin NB, Goode LB, Fearnot NE, Smith HJ. Intravascular lead extraction using locking stylets and sheaths. Pacing Clin Electrophysiol. 1990;13:1871-5.

9. Kennergren C, Schaerf RH, Sellers TD et al. Cardiac lead extraction with a novel locking stylet. J Interv Card Electrophysiol. 2000;4:591-3.

10. Golzio PG, Bongiorni MG, Giuggia M, Vinci M, Gazzera C, Breatta AD. Retrieval of pacemaker lead tip embolized into the distal pulmonary arterial bed during extraction procedure. Pacing Clin Electrophysiol. 2007;30:1558-61.

11. Calvagna GM, Evola R, Valsecchi S. A complication of pacemaker lead extraction: pulmonary embolization of an electrode fragment. Europace. 2010;12:613.

12. Wilkoff BL, Love CJ, Byrd CL et al. Heart Rhythm Society; American Heart Association. Transvenous lead extraction: Heart Rhythm Society expert consensus on facilities, training, indications, and patient management: this document was endorsed by the American Heart Association (AHA). Heart Rhythm. 2009;6:1085-104.

13. Raatikainen MJ, Perälä J, Lahtinen J. Successful defibrillator lead remnant extraction from right ventricle using a steerable transseptal sheath and a basket retriever. Europace. 2009;11:1238-40.

14. Eckart RE, Hruczkowski TW, Landzberg MJ, Ames A, Epstein LM. Pulmonary arterial embolization of pacemaker lead electrode tip. Pacing Clin Electrophysiol. 2006 Jul;29(7):784-7

15. Kutarski A, Pietura R, Czajkowski M. Breakage of extracted leads: another management option. Kardiol Pol. 2012; 70(3):307-12 